\title{
1 How waves are accelerating global coastal overtopping
}

2 Rafael Almar ${ }^{1,}{ }^{*}$, Harold Diaz ${ }^{1}$, Erwin W.J. Bergsma ${ }^{1}$, Roshanka Ranasinghe ${ }^{2,3,4}$, Angelique Melet ${ }^{5}$,

3 Fabrice Papa ${ }^{1}$, Michalis Vousdoukas ${ }^{6}$, Panagiotis Athanasiou ${ }^{3,4}$, Olusegun Dada ${ }^{7}$, Luis Pedro

4

\section{Almeida $^{8}$, and Elodie Kestenare ${ }^{1}$}

${ }^{1}$ LEGOS (CNRS/IRD/CNES/Toulouse University), Toulouse, France

2Department of Coastal and Urban Risk @ Resilience, IHE Delft Institute for Water Education, P.O. Box 30152610 DA

Delft, The Netherlands

${ }^{3}$ Harbour. Coastal and Offshore Engineering, Deltares, PO Box 177, 2600 MH Delft, The Netherlands

${ }^{4}$ Water Engineering and Management, Faculty of Engineering Technology, University of Twente, PO Box 217, 7500 AE

Enschede, The Netherlands.

${ }^{5}$ Mercator-Ocean, Toulouse, France

${ }^{6}$ European Commission, Joint Research Centre (JRC), Ispra, Italy

${ }^{7}$ Federal University of Technology, Akure, Nigeria

${ }^{8}$ Universidade Federal do Rio Grande do Sul, Rio Grande, Brazil

Corresponding author ${ }^{*}$ rafael.almar@ird.fr

\section{ABSTRACT}

The world's coastal areas are home to about $10 \%$ of the human population and support unique and dynamic ecosystems, offering $€$ trillions worth of environmental and societal benefits. Climate change and anthropogenic pressures are however exacerbating devastating hazards such as episodic coastal flooding, the magnitudes of which remain highly uncertain to date. This study, for the first time, presents global scale coastal overtopping estimates, which account for not only the effects of sea level rise, storm surge and wave setup as traditionally done, but also that of wave runup and existing coastal protection measures. While the latter are widely recognized as important determinants of episodic coastal flooding, they have hitherto been ignored in assessments thereof. Our results show that the combination of tides and large wave runup events is the main contributor to episodic coastal overtopping. The Gulf of Mexico, northern Europe, Mediterranean region, east coast of Africa, south east Asia, and north western Australia emerge as hotspots of episodic coastal overtopping under the current climate. Future projections of overtopping with the the global mean sea level rise under "businessas-usual" scenario RCP 8.5 indicate that the globally integrated number of annual overtopping hours will increase at a rate faster than that of the global mean sea level rise itself. This study also shows that, under the RCP 8.5 sea level rise trajectory, the projected acceleration in coastal overtopping should be starting about now and will be clearly discernible by about 2050. Global overtopping has increased almost by 1.5 from 1993 by now and will reach values more than 50 times larger by the end of the $21^{\text {st }}$ century. The global projections presented here are anticipated to lay a solid foundation for the development of effective climate adaptation measures at the identified hotspots, ideally through detailed local scale studies. 


\section{Context}

Coastal flooding is threatening human societies (Hinkel et al., 2014; Vousdoukas et al., 2018) and infrastructures (Koks et al., 2019) and sea level rise is expected to exacerbate the situation in the decades to come. Over the next few decades, sea level rise is projected to double the frequency of coastal flooding (Vitousek et al., 2017) possibly affecting an estimated global population of nearly 1 billion people (Nicholls and Small, 2002; Neumann et al., 2015; Kulp et al., 2019). Regions with limited water-level variability, i.e., short tailed flood-level distributions, that are located mainly in the Tropics, are likely to be the most affected (Vitousek et al., 2017). In particular, the low-lying coasts of Africa and Asia are thought to be the most vulnerable areas worldwide, at which an increase in flood occurrence could force population migration (Nicholls and Cazenave, 2010). Without appropriate flood mitigation strategies, sea level rise will increase the frequency and magnitude of flooding events (Tebaldi et al., 2012; Vitousek et al., 2017; IPCC report, 2018).

Total water level (EWL) at the coast results from several contributions (Figure 1). The main contributors differ according to time scales and region; they include contributions by regional sea level ocean governed by the steric effect and circulation (here referred as $S L A)$, storm surge due to atmospheric pressure and winds $(D A C)$, astronomical tide $(A T)$ and wave effects here named runup $(R)$ including a time-averaged component (setup) and an oscillatory component (swash) (see Melet et al., 2018).

$$
T W L=S L A+D A C+A T+R
$$

Despite the important role that ocean waves play in determining total water level at the coast (Beetham and Kench, 2018; Melet et al., 2018) via wave setup and wave runup, their contribution is still largely ignored or underestimated in most studies, mainly due to the lack of global information on detailed coastal topography, knowledge of which is required to compute the wave contributions accurately. Topographic and foreshore slope data available till now, excepting for small local data sets acquired for site specific studies, are often very coarse, outdated or simply non-existent in large parts of the world, leading to inaccurate estimates of flooding and associated risks to coastal populations. Owing to this, global studies (Vitousek et al., 2017; Beck et al., 2018; Melet et al., 2018; Vousdoukas et al., 2018) that do account for the contribution of waves to sea level at the coast are still based on highly simplified coastal topography/bathymetry (e.g. constant slope worldwide). While many studies have acknowledged that local topography and foreshore slope can influence flood exposure and risk greatly (Vousdoukas et al., 2018; Luijendijk et al., 2018; Hauer et al., 2020; Minderhoud, 2019; Kulp et al., 2019), no concerted effeorts have been taken to address this shortcoming to date.

In this study, we overcome this long-felt need by combining a new state-of-the-art global digital surface model (ALOS World 3D - 30m AW3D30, JAXA - Tadono et al., 2016; Zhang et al., 2019) with water level variations at the coast derived from a combination of satellite altimetry, tide and surge models and wave reanalyses, including the important contribution of wave runup. Using these data, we present, for the first time, global scale estimates of the acceleration of overtopping in recent decades and under one high-end sea level rise scenario. 


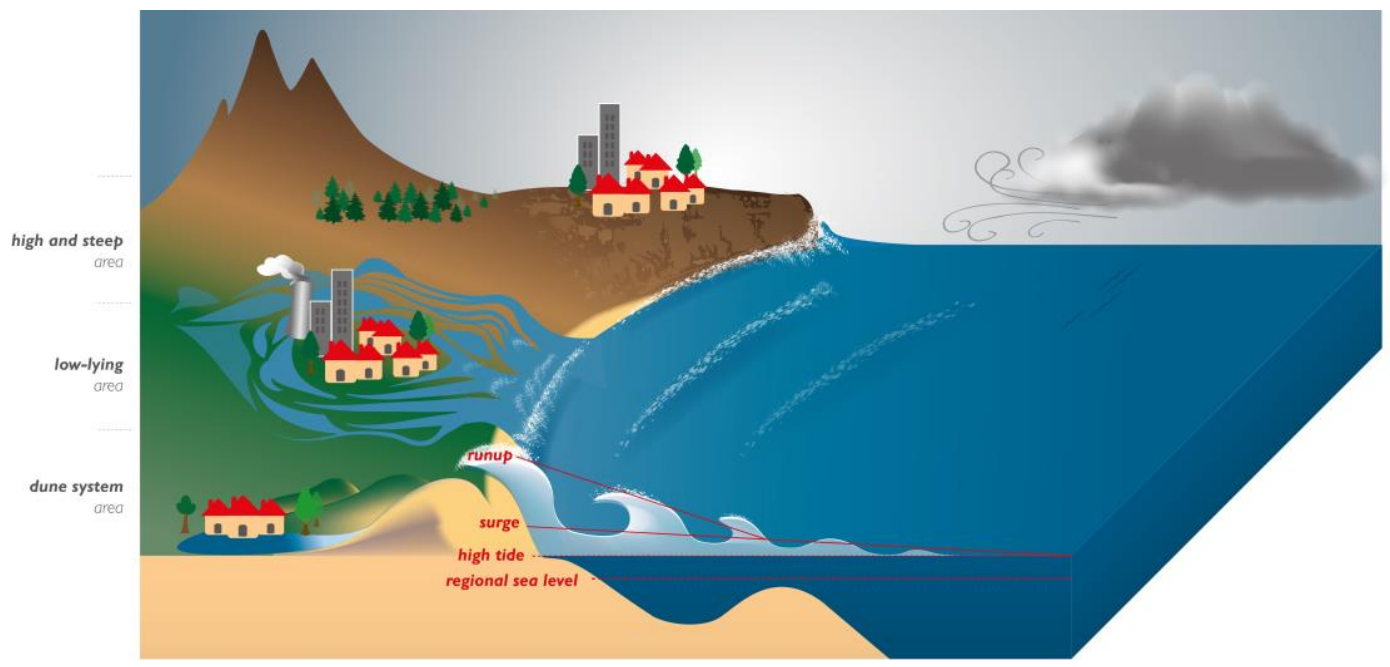

Figure 1. Schematic of process governing coastal overtopping and different levels of consequent flooding depending on type of coastal topography. Total water level at the coast results from several contributions: regional sea level governed by the steric effect and circulation (here referred as $S L A$ ), astronomical tide (AT), surge due to atmospheric pressure and winds $(D A C)$ and wave runup $(R)$, decomposed into a time-averaged component (setup) and an oscillatory component (swash) (see Melet et al., 2018).

\section{World coastal morphology}

The length of the global coastline exceeds 1.6 million kilometers (Burke et al., 2001) including open coasts, bays, lagoons and estuaries. Among these coastlines, sandy beaches (fine to coarse sand) represent $\sim 31 \%$ of ice-free world coasts (Luijendijk et al., 2018, Vousdoukas et al., 2020). In general, sandy beach slopes range from 0.01 (for finer sediment) and 0.2 (for gravel beaches) (Poate et al., 2016). For these sandy beaches, as a rule of thumb, the wave setup is $20 \%$ of offshore wave height (Stockdon et al., 2006; Dodet et al., 2019). At rocky coasts with rocky platforms, wave runup is important but reduced by bottom friction over the rocky bottom (Dodet et al., 2018).

Coastal morphology has been modified in various ways by human activities, particularly in urbanized areas in which, for example ports have been constructed, seawalls built to combat coastline recession, cliffs stabilized, and groins placed in an attempt to retain a beach fringe and maintain dunes (Serafin et al., 2019). These human interventions to the natural system generally have steepened coastal slopes (e.g. seawalls, dikes), resulting in smaller wave dissipation zones compared to natural coasts. Variations in sediment budgets, due to, for example, fluvial sediment retention by dams (Anthony et al., 2015; Latrubesse et al., 2017; Besset et al., 2019; Ranasinghe et al., 2020), urbanization and certain land use practices (agriculture, deforestation of mangroves; see Luijendijk et al., 2018; Mentaschi et al., 2018), have also made coastal zones highly vulnerable to overtopping and consequent flooding (MacGranahan et al., 2007; Adelekan, 2010; Appeaning Addo et al., 2011).

Figure 2 shows the global distribution of the key coastal topographical parameters used in this study (see Data and Methods for the steps followed to obtain these parameters). The coastal elevations shown in Figure 2(a) are the maximum subaeral coastal elevations (including dunes and coastal structures). The global average value of the subaerial beach slope 
is $\sim 0.1$ (median $\sim 0.04$ ), covering different types of coastlines (Figure 1) including open sandy beaches, barrier islands, cliffs, river deltas, and engineered beaches (Schwartz, 2003). Regional patterns are clearly visible, such as the along-coast gradient in beach slope along the west coast of North America, from relatively low (0.04) in the tropics to steep (0.15) in high latitudes. Similar features are observed in the southern hemisphere. Africa, the continent with the largest length of sandy coasts, generally has low-lying coastlines with gentle slopes. Interestingly, coastal elevation (see computation method in the Data and Methods Section) appears to generally increase with latitude, while island archipelagos such as Indonesia and Japan show high variability of slope/elevation within small distances (Figure 2).

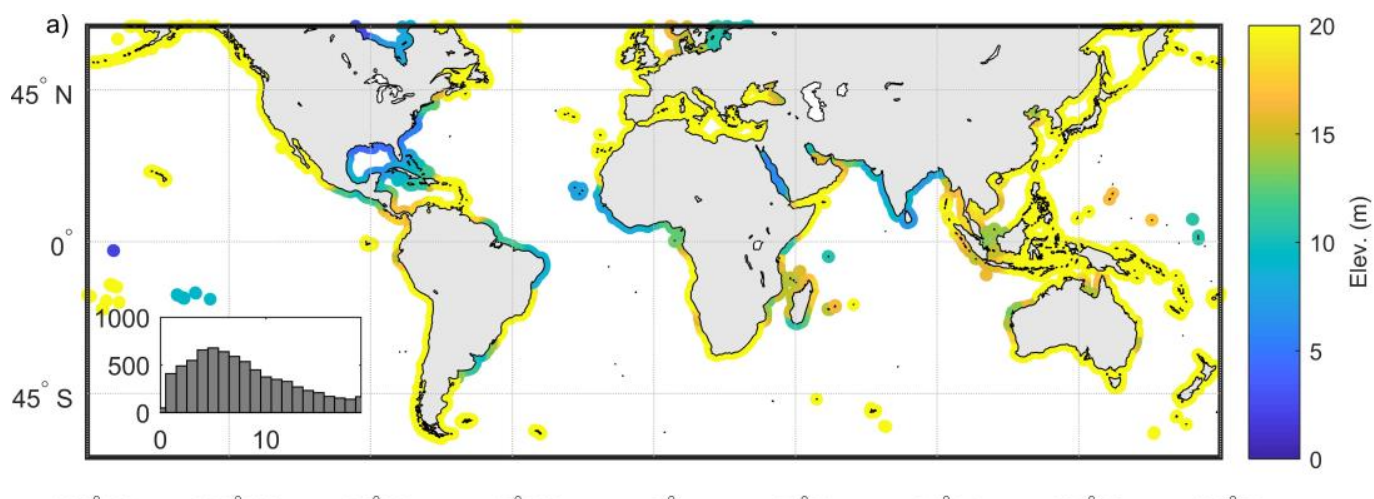

$180^{\circ} \mathrm{W} \quad 135^{\circ} \mathrm{W} \quad 90^{\circ} \mathrm{W} \quad 45^{\circ} \mathrm{W} \quad 0^{\circ} \quad 45^{\circ} \mathrm{E} \quad 90^{\circ} \mathrm{E} \quad 135^{\circ} \mathrm{E} \quad 180^{\circ} \mathrm{E}$

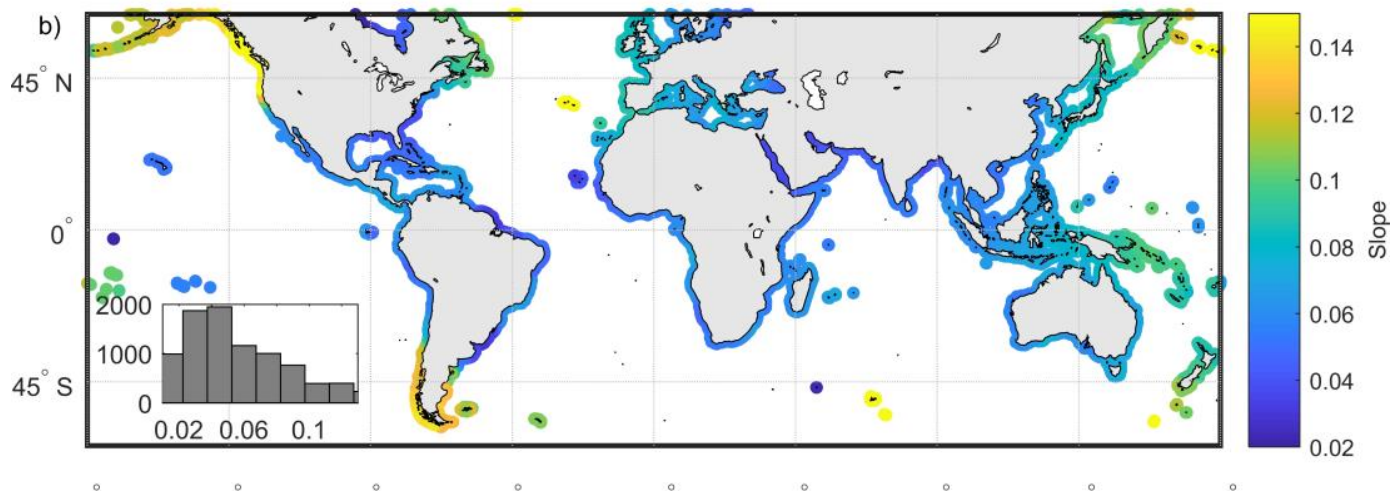

\section{Overtopping events}

Overtopping occurs when the coastal water level exceeds that of the crest level of natural (e.g. dunes) or artificial (e.g. dykes) coastal defenses. Here we used Eq. 1 to compute total water levels over the 23-year period between 1993 and 2015. The way in which each term in Eq. 1 is described in detail in the Data and Methods section. Nevertheless, for the convenience of the reader, here a very brief description is given. 
Non-peer reviewed EarthArXiv preprint

In all, Eq. 1 was applied at 14,140 coastal profiles around the world. Regional sea level (SLA) at each computational profile was derived from satellite altimetry sea level time series from the SSALTO/DUACS multimission data (Pujol et al., 2016). Storm surge values (DAC) for the study period were taken from a global application of the MOG2D-G model (Carrere et al., 2014), forced with ERA-interim winds and surface atmospheric pressure. Astronomical tides (AT) were taken from the global tide model FES (Carrere et al., 2014). Wave runup ( $R$, which here includes both wave setup and the oscialltory swash component) was computed using two forms (for steep and mild slopes) of the commonly used Stockdon et al. (2006) parameterization together with ERA-interim wave data.

Figure 3.a shows the estimated total annual overtopping hours, averaged over 23 years (1993-2015), noting that these results do not account for small-scale coastal defences that are not resolved by the satellite-based AW3D30 data set. A few exposed low-lying regional hot-spots are evident in South East Asia, Northern Europe, Southern Mediterranean coast, and Eastern-US. Among these, the low-lying sedimentary plains such as deltas (e.g. Bengal, Nile and Mississippi Deltas for instance, see Nicholls et al., 2007 and Besset et al., 2019) emerge as the areas in the world that are most threatened by episodic coastal flooding. A detailed validation of our methodology for selected historical events (e.g. Katrina in USA, Xynthia in Europe/France) is provided in Supplementary Material Section 3.

Figure 3.b shows that, over the period 1993-2015 there has been an increasing trend in the total annual overtopping hours in most parts of the world. A few areas appear to have experienced a small trend, mainly in the mid to high latitudes: West coast of North America, North Europe, and the South East coast of South America. The increasing trends are mainly in the tropics, as also observed by Vitousek et al. (2017) and Vousdoukas et al. (2018); e.g. The Gulf of Mexico, northern Europe, Mediterranean region, east coast of Africa, south east Asia, and north western Australia. This might be explained by the fact that in some of these regions generally have little variability in total water level (variance of the time series), and hence, even small increases in sea level (regional relative sea level rise) have a bigger impact on overtopping (Rueda et al., 2017). In the Pacific Basin, the increasing trend on the Western side and a decreasing trend on the Eastern side is noteworthy, as is the strong increasing trend in the Western Indian Ocean along Madagascar and Africa coastlines such as Mozambique. Similar behaviour is also observed in the North Atlantic with a decreasing trend on the Western side and an increasing trend on the Eastern side. Supplementary Figure $\mathbf{S 2}$ shows the trends in wave runup, regional sea level and atmospheric tide separately, indicating that the individual components have contrasting regional patterns. In some areas (e.g. Caribbean, Bay of Bengal, Mekong delta) the contribution of all individual components add up to result in a higher overall trend of overtopping events, whereas in other areas (e.g. North Western Europe, southeastern coast of North America), some components cancel out the effect of others to result in small or negative trends in overtopping events. 

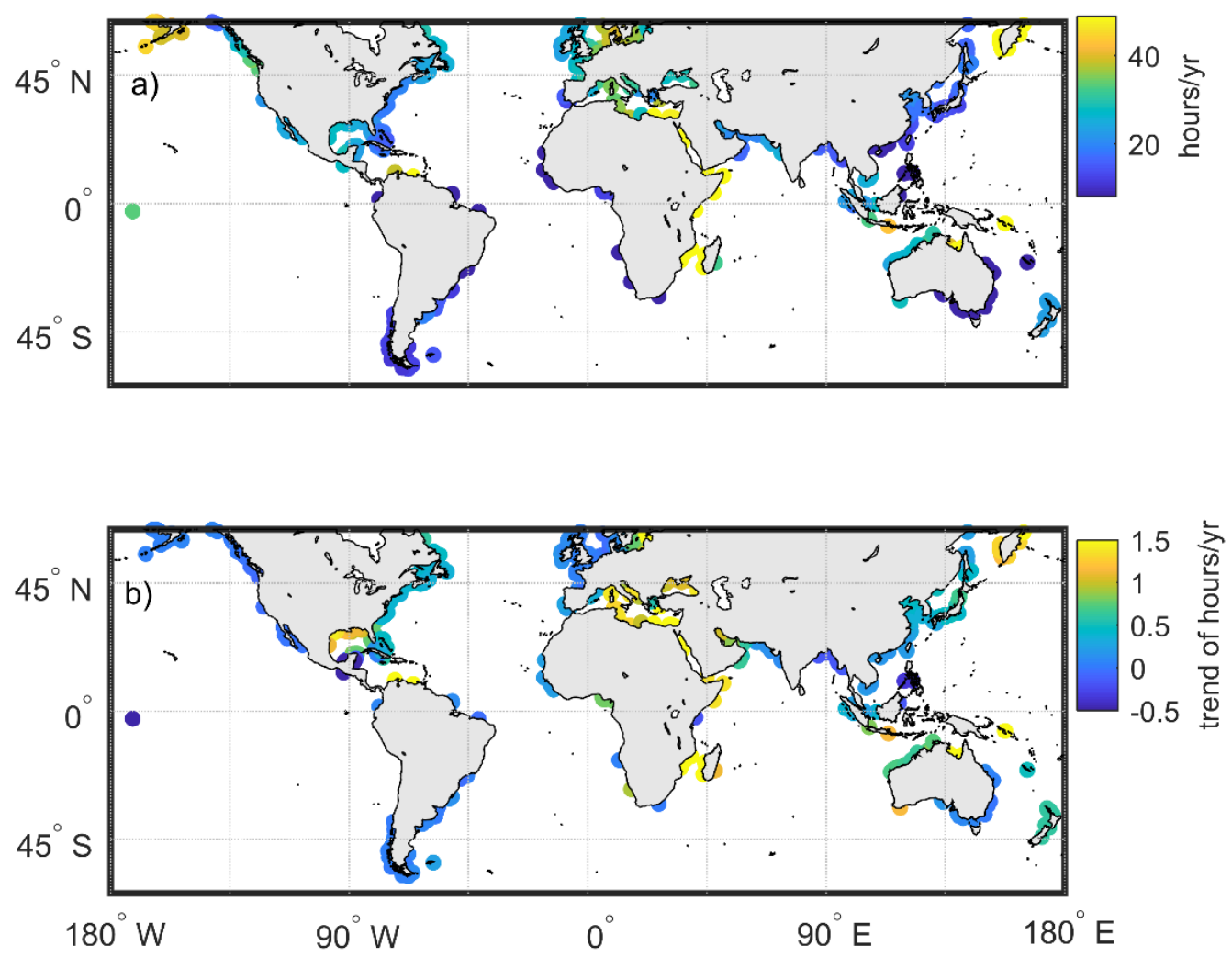

Figure 3. Global map of coastal overtopping (number of hours per year): a) occurrence and b) 23 year trend of occurrences (see methods for details on computation approach adopted).

Figure 4 shows the globally integrated number of annual overtopping hours (black), the contribution to overtopping from wave runup and tide (not including regional sea level and surge) (blue), and the contribution to overtopping from regional sea level, surge and tide (no waves) (red). Figure 4a indicates that wave runup+tide is the dominant contributor to the annual number of overtopping hours, although they, on their own, do not induce a positive significant trend in overtopping hours (the absence of current global trend in waves is also mentioned in Melet et al., 2018). It is the combination of all the components that induces an increase (significant at 95\% level using Mann-Kendall test) of the globally integrated number of annual overtopping hours over the past 23 years. Global overtopping has increased almost by 1.5 from 1993. 

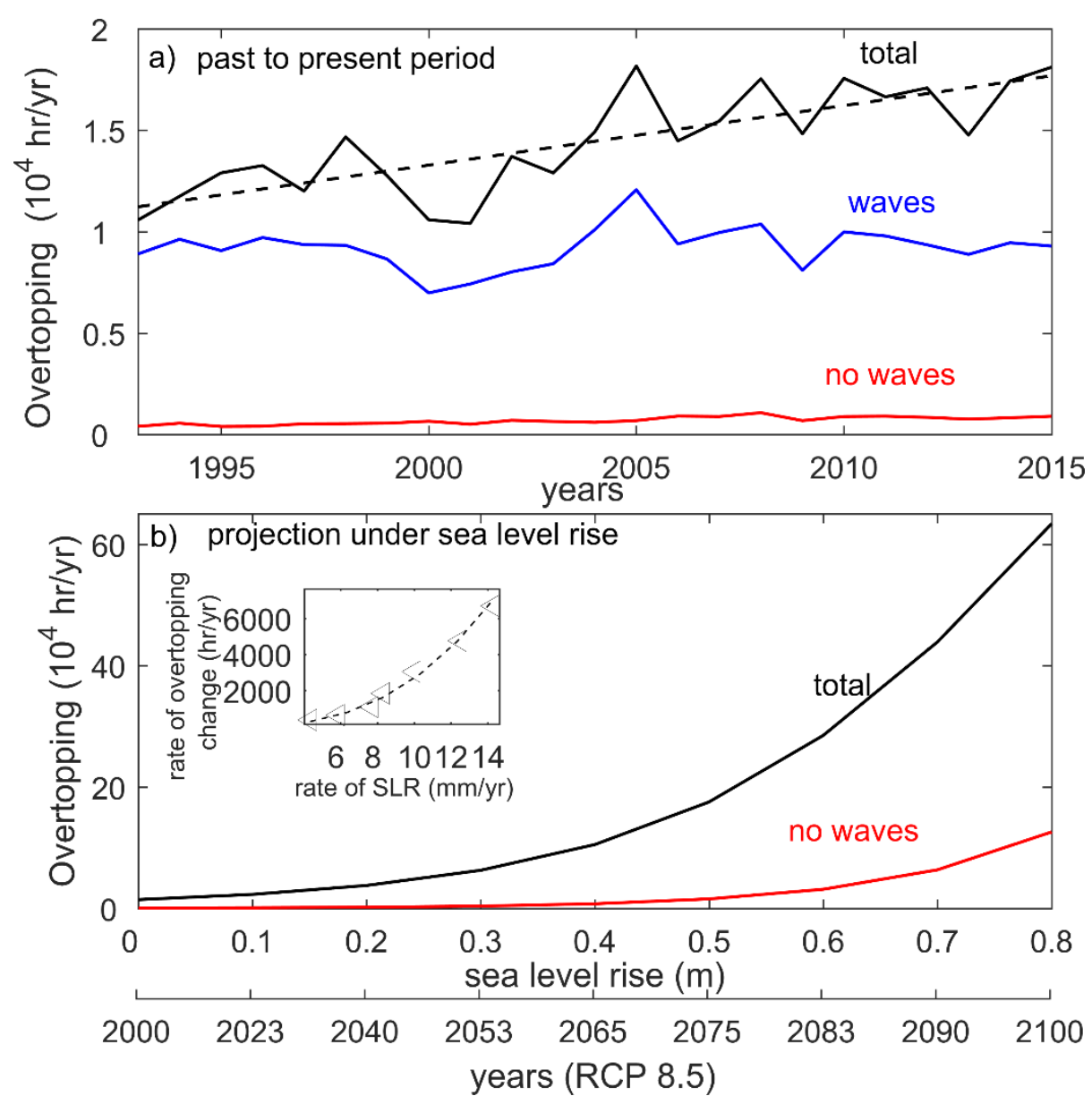

Figure 4. a) Globally integrated number of annual overtopping hours (solid black line) together with its linear regression (dashed line) (significant at 95\% level), contribution to overtopping from waves and tide only (solid blue line), and the contribution to overtopping excluding waves (solid red line). b) Globally integrated number of annual overtopping hours (solid black line) and annual overtopping hours when the wave contribution is excluded (solid red line) under the global mean sea level rise projected for the Representative Concentration Pathways ("business-as-usual") RCP 8.5 (median projection, IPCC AR5 WGI SPM). Insert in b) compares the rates of changes of sea level rise (in $\mathrm{mm} / \mathrm{yr}$ ) with the rate of overtopping (in hours/yr). Triangles are computed values and dashed line is the fitted exponential regression $\left(R^{2}=0.8\right)$ evidencing a law in $\exp (2.7)$ between the two.

The way in which sea level rise may influence the above presented current climate coastal overtopping characteristics was investigating by computing the change in the annual overtopping hours between year 2000 and 2100, under the median sea level rise projection for the Representative Concentration Pathways ("business-as-usual") RCP 8.5 (IPCC AR5 WGI SPM). Figure 4.b shows that, in a globally aggregated sense, if wave runup were not to be considered in computations, the total annual overtoping hours by 2100 would be underestimated by over $40 \%$. Figure $4 . \mathbf{b}$ also shows that, when the wave contribution is included in the computation, a noticeable sea level rise driven increase in overtopping hours is estimated to have already started (in around 2020), as indicated by the upward inflection in the black line around 2020, while without wave contributions, a noticeable increase in overtopping hours is only expected to commence around 2075. These future 
Non-peer reviewed EarthArXiv preprint

pojections indicate that the inevitable sea level rise driven increase of global overtopping will be accelerated by the effect of wave runup, with values more than 50 times larger by the end of the 21st century than for the present period.

\section{Discussion and looking forward}

Here, we combine fine-scale global coastal topography from recently developed global satellite-based products with stateof-the-art computations of total water level at the coast (including wave contributions) to quantify overtopping exposure worldwide, both for the present and the future. We demonstrate that overtopping events are in fact mainly due to the combined effect of large wave runup events and high astronomical tides. However, these contributing processes by themselves do not induce a significant trend in the globally integrated number of annual overtopping hours, rather, it is the combination of regional sea level, wave runup and tide that results in an increase of this quantity. Thus, our results re-affirm the previously reported (Prime et al., 2016; Serafin et al., 2017) finding that sea-level rise will have a greater impact on 21st century coastal flooding than future changes in wave climate). The interaction of sea level and topography increases overtopping events at a rate faster than sea level rise itself with a found exponential factor of 2.7 with SLR. Under the RCP 8.5 sea level rise trajectory, the projected acceleration in coastal overtopping should be starting about now and will be clearly discernible by about 2050 .

It should be noted that waves have a significantly different impact on open coasts than on deltas. Recent studies have shown that waves might have a complex influence on flooding at inlets and estuaries, in combination with local hydrology and other sea level contributions deriving from met-ocean forcing (Tazkia et al., 2017; Lashley et al., 2019), but these processes could not be accounted for in our global scale study. Moreover, local precipitation or river discharge can lead to compound flood events wen thet occur concurrently with storm surge and large wave runup events (Brammer, 2014; Ward et al., 2018; Moftakhari et al. 2017; Paprotny et al., 2020). Again due the the global focus of this study, such compound flooding events, which are heavily dependent on local phenomena, could not be taken into account in this study.

Global scale coastal flooding studies currently face a double observational bottleneck. On one hand, it is currently impossible to observe sea levels at the coast, in particular wave contributions. On the other hand, accurate measurements of regional morphological evolution (Serafin et al., 2019; Mentaschi et al., 2018) and subsidence trends (Becker et al., 2018) also cannot be currently obtained from ground-based GPS stations and satellite surface tracking (altimeter or stereo imagery). Of these, at least the former challenge will however beaddressed to some degree by the NASA/CNES altimetry mission Surface Water and Ocean Topography (SWOT), planned for 2021). This mission is expected to accurately monitor water levels in the coastal zone at high resolution (<100 m, see Durand et al., 2010). The recently launched NASA mission IceSat-2, with its 90-day global revisit and fine resolution ( $0.7 \mathrm{~m}$ along track, $70 \mathrm{~m}$ cross track, $30 \times 30 \mathrm{~m}$ final products) will also help address this challenge.

The global scale of the analysis presented here imposes some further inevitable simplifications in the wave runup calculation; accurate modelling of flooding during storm surges has been conducted at regional scale (Krien et al., 2017; Vousdoukas et al., 2018) but modelling wave propagation to nearshore is a challenge in itself, primarily because coastal bathymetry is generally outdated or unknown at most of the coastlines. Even if detailed present day bathymetry were 
Non-peer reviewed EarthArXiv preprint

available, past and future bathymetry would still remain unknown. As a result, this and other recent global studies, use a fixed coastal bathymetry over time periods spanning 50-100 years. However, coastal systems are among the most dynamic geological environments on Earth at various time scales, with, for e.g a single large storm being able to reshape regional bathymetry which could significantly affect instantaneous total water levels at the coast in subsequent years. Thus the consideration of passive coastal bathymetry over a 100 years in this and other global studies necessarily assumes that computed coastal flooding is an exclusive response to water levels (Le Cozannet et al., 2019; Serafin et al., 2019).

Finally, here we have used only global mean sea level rise projections in our future overtopping computations. However, regional variations in sea level can be significant (Church et al., 2013; Slangen et al., 2014), while local phenomena such as vertical land movement (e.g. land subsidence) can in places result in relative sea level rise rates that are far greater than the gloal mean rate (e.g. Jakarta, New Orleans, Ho Chi Minh City) (Nicholls et al., 2014). Consideration of these regional and local contributions to relative sea level rise will affect coastal flooding projections for certain specific locations, in particular at coastal cities and low lying deltas (Hallegatte et al., 2013; Erkens et al., 2015 Brown and Nicholls, 2015; Kulp and Strauss, 2019; Becker et al., 2020).

\section{Data and Methods}

\section{AW3D30 Global Digital Surface Model}

Here we used the new and freely available ALOS Global Digital Surface Model (ALOS World 3D - 30m, JAXA - Tadono et al., 2016; Zhang et al., 2019), known as AW3D30. This database is used here with its maximum freely available resolution of 1 arc-second (i.e. approximately $30 \mathrm{~m}$, while commercial AW3D PRISM resolution is $5 \mathrm{~m}$ ). The surface model was acquired over the 2006-2011 period using optical stereo-based photogrammetry and has been made publicly available at $30 \mathrm{~m}$ resolution. The AW3D30 product is created as a digital surface model converted from the GRS80 ellipsoid height based on the ITRF97 coordinate system, using the EGM96 geoid model. Our analysis is restricted to the coverage of AW3D30, from 60 degrees north to 60 degrees south. High latitudes associated with no-data or low-quality area are discarded in this analysis.

A comparson of results obtained using AW3D30 againts those obtained using a different independent dataset, from the MERIT and GEBCO topo-bathymetry dataset (Athanasiou et al., 2019) is presented in the Supplementary Material Section 2. This latter dataset was used in the study to obtain foreshore slopes that are required as input for the wave runup formulae. To account for artificial coastal protection, the FLOod PROtection Standards FLOPROS (Scussolini et al., 2016) dataset was used as a third estimate of maximum subaerial coastal elevations (Vousdoukas et al., 2018).

\section{Coastal topography extraction}

Maximum subaerial coastal elevation and coastal slopes were extracted from the above-mentionned MERIT and AW3D30 dataset along the global coastline. Here, the Global Self-consistent, Hierarchical, High-resolution Geography Database (GSHHS - Wessel and Smith, 1996) coastline "h" highest resolution ( kilometric) was used. Coastal shoreline and topography are highly variable alongshore. In order to obtain reasonably robust estimates, cross-shore aerial topography profiles were extracted every 0.05 degrees (see Figure 5). From these, a "median profile" was calculated every 0.5 degrees to construct the profiles ultimately used in the analysis to bring down the compuatational demands to a manageable level. Islands with 
a circumference less than 0.5 degrees were excluded from the analysis, as we deemed it sufficient at a global scale and representative of the regional values seen in the literature. This results in a total of 14140 profiles at which the analysis was performed.

The topographic slope and maximum elevation on each analysis profile were calculated using an automated detection method. In this method, first, the local sea-land orientation of each profile was identified, based on the average topography values on the two sides of the shoreline: the higher side is taken to be land and lower to be sea. On each transect, the highest coastal point (e.g. dune, cliff top, crest of structure) was approximated as the closest local maximum landward of the determined shoreline (see Figure 5). The slope used in the wave contribution calculations is estimated as the average slope within the region determined by the shoreline and the distance given by the coast high, following the method developed in Diaz et al. (2019) - see insert in Figure 5.

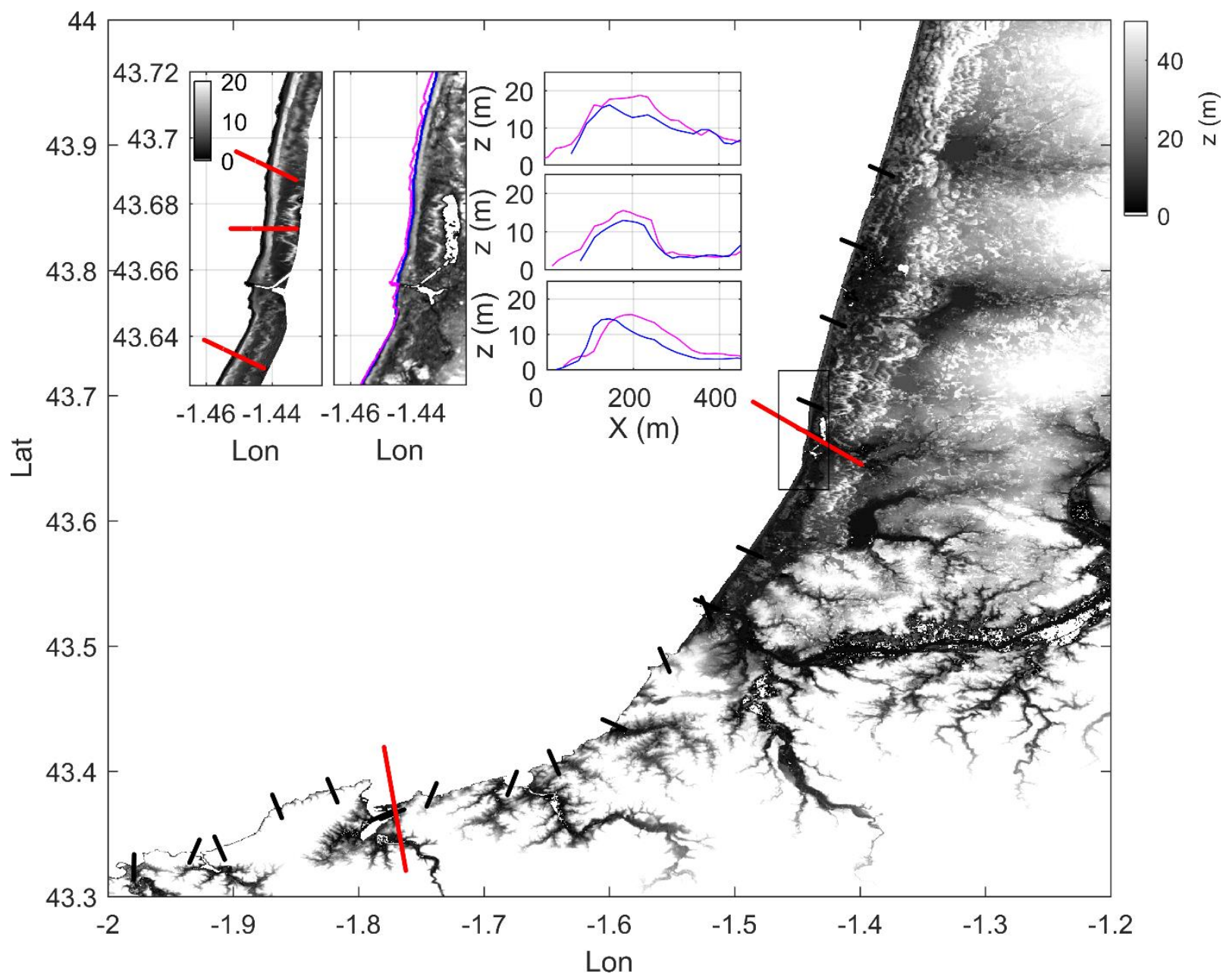

Figure 5. Regional AW3D30 topography in SW France compared to airborne LIDAR measurements that serves as reference topography (from Diaz et al., 2019). Black and red represent cross shore profiles examples of fine and coarse resolution, respectively. Insert shows LIDAR and AW3D30 maps and different profiles (red transects). Magenta and blue lines stand for LIDAR and AW3D30 datasets, shoreline and cross-shore transects. 


\section{Components of sea level at the coast}

Altimetry sea-level timeseries (SLA in Eq. 1) are extracted from the gridded daily maps produced by the SSALTO/DUACS multi-mission (Pujol et al., 2016) and distributed by the Copernicus Marine Environment Monitoring Service (Le Traon et al., 2019) using the closest points to the coast therein. Atmospheric variables (surface winds, sea level pressure) and wave data (significant height $\mathrm{Hs}$ and peak period $\mathrm{Tp}$ ) are extracted from the ERA-interim data base, developed by the European Centre for Medium-Range Weather Forecasts model (ECMWF, the WAMDI Group, 1988), at 0.5x0.5 degrees and 6-hr temporal resolution between 1993 and 2015. The ERA-Interim reanalysis uses an ocean wind-wave model coupled to the atmosphere, which has been extensively validated (Sterl and Caires, 2005; Caires et al., 2006; Dee et al., 2011). Surges (named DAC in Eq. 1) were extracted from the dynamical atmospheric correction applied to altimetric data, provided by the MOG2D-G barotropic model forced by ERA-interim surface winds and the inverse barometer effect with data outputs at a 6-hourly temporal resolution. Astronomical tide elevations (named AT in Eq. 1) were obtained from the global tide model FES (Finite Element Solution - Carrere et al., 2014). Tide predictions were derived with hourly temporal resolution using the closest points to the coast. Wave runup ( $R$ in Eq. 1) is computed from the conventional and commonly used parameterization by Stockdon et al. (2006), where $R$ is given as a function of deep-water significant wave height $H_{s}$, wave length (Lo), and topography slope (6). Here, Stockdon et al's (2006) parametrization was used in two forms depending on the ration between the relative coastal slope and incident waves as described by the Irribarren number $\xi=\tan (\beta) /\left(H_{s} / L_{o}\right)(\operatorname{Iribarren}$ and Nogales, 1949):

- $\quad$ Eq. 2 at coasts with $\xi<0.3$ :

$$
R=0.043 \sqrt{H_{S} L_{o}}
$$

- $\quad$ Eq. 3 at coasts with $\xi>0.3$ :

$$
R=1.1\left(0.35 \beta \sqrt{H_{s} L_{o}}+0.5\left[H_{s} L_{p}\left(0.5625 \beta^{2}+0.004\right)\right]^{1 / 2}\right)
$$

Stockdon et al.'s (2006) parametrization was developed for and is applicable for sandy beaches. It is however commonly used for different environments, such as gravel beaches (Poate et al., 2016), rocky coasts (Dodet et al., 2018), on structures (Atkinson et al., 2017), with reasonable demonstrared skill in predicting wave runup (Dodet et al., 2019). For example, the autmated computation procedures used in this study would ensure that Eq. $\mathbf{3}$ would be used at steep profiles such as would be the case where coastal defense strutures are present, whereas on natural beaches with milder slopes, Eq. $\mathbf{2}$ would be used.

\section{Method to compute overtopping}

Using the above described dataset, the different contributions to total water level, including wave runup, were calculated over the 1993-2015 period every hour. Overtopping is defined when the total instantaneous water level thus computed exceeded the maximum coastal elevation, potentially causing flooding. To temporally-aggregate the event level information, the number of hours of water level occurences exceeding the maximum coastal elevation threshold is counted at each point 
for every year The sensitivity of the overtopping projections to the choice of the topography dataset (i.e. AW3D30, MERITGEBCO, FLOPROS) was investigated and shown in Suppmementary Figure S5.

\section{Data availability}

The SSALTO/DUACS altimeter products were produced and distributed by the Copernicus Marine Environment Monitoring Service (http://marine.copernicus.eu/). Dynamical atmospheric corrections were produced by the Collecte Localisation Satellites Space Oceanography Division using the MOG2D model from Laboratoire d'Etudes en Géophysique et Océanographie Spatiales (LEGOS) and distributed by AVISO (Archiving, Validation and Interpretation of Satellite Oceanographic data), with support from Centre National d'Etudes Spatiales (CNES) (http://www.aviso.altimetry.fr/). FES2014 tidal data are produced by LEGOS. Tide gauge data were downloaded from the University of Hawaii Sea Level Center (https://uhslc.soest.hawaii.edu/data). ERA-Interim data were produced by the European Centre for Medium-Range Weather Forecasts (https://www.ecmwf.int/en/forecasts/datasets/reanalysis-datasets/era-interim).

\section{References}

Adelekan, I. O. Vulnerability of poor urban coastal communities to flooding in lagos, nigeria. Environ. Urbanization 22, DOI: doi:10.1177/0956247810380141 (2010).

Anthony, E., Brunier, G., Besset, M. et al. Linking rapid erosion of the Mekong River delta to human activities. Sci Rep 5, 14745 (2015). https://doi.org/10.1038/srep14745

Appeaning Addo, K., Larbi, L., Amisigo, B. \& Ofori-Danson, P. K. Impacts of coastal inundation due to climate change in a cluster of urban coastal communities in ghana, west africa. Remote. Sens. 3, 2029-2050, DOI: 10.3390/rs3092029 (2011).

Athanasiou, P., van Dongeren, A., Giardino, A., Vousdoukas, M., Gaytan-Aguilar, S., and Ranasinghe, R.: Global distribution of nearshore slopes with implications for coastal retreat, Earth Syst. Sci. Data, 11, 1515-1529, https://doi.org/10.5194/essd-11-1515-2019, (2019).

Atkinson, A. L. et al. Assessment of runup predictions by empirical models on non-truncated beaches on the south-east australian coast. Coast. Eng. 119, 15 - 31 (2017).

Beck, M.W., Losada, I.J., Menéndez, P. et al. The global flood protection savings provided by coral reefs. Nat Commun 9, 2186 (2018). https://doi.org/10.1038/s41467-018-04568-z

Becker, M., Karpytchev, M. \& Papa, F. Hotspots of relative sea level rise in the tropics. Trop. Extrem. Nat. Var. Trends 9780128092484 (2018).

Becker, M., Papa, F., Karpytchev, M., Delebecque, C., Krien, Y. et al.. Water level changes, subsidence, and sea level rise in the Ganges-Brahmaputra-Meghna delta. Proceedings of the National Academy of Sciences of the United States of

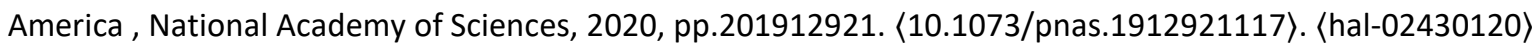


Beetham, E. P. \& Kench, P. Predicting wave overtopping thresholds on coral reef-island shorelines with future sea-level rise. Nat. Commun. (2018).

Besset, M., Anthony, E.J. , Bouchette, F., Multi-decadal variations in delta shorelines and their relationship to river sediment supply: an assessment and review. Earth Sci. Rev. (2019), 193-199-219

Brammer, H. Bangladesh's dynamic coastal regions and sea-level rise. Clim. Risk Manag. 1, 51-62 (2014).

Brown, S. \& Nicholls, R. Subsidence and human influences in mega deltas: The case of the ganges-brahmaputra-meghna. Sci. The Total. Environ. 527-528, $362-374$ (2015).

Burke, L. et al. Pilot analysis of global ecosystems: coastal ecosystems. World Resour. Institute, Wash. DC 93 pp (2001).

Caires, S., Swail, V. \& Wang, X. Projection and analysis of extreme wave climate. J. Clim. 19(21), 5581-5605 (2006).

Carrere, L., Lyard, F., Cancet, M., Guillot, A. \& Picot, N. Fes 2014, a new tidal model - validation results and perspectives for improvements. Present. to ESA Living Planet Conf. Prague 2016 137, 553-597 (2014).

Church, J. A. et al. Sea-level rise by 2100. Science 342, 1445, DOI: doi:10.1371/journal.pone.0118571 (2013).

Dee, D. \& et al. The era-interim reanalysis: configuration and performance of the data assimilation system. Q. J. R. Meteorol. Soc. 137, 553-597 (2011).

Diaz, H., Almar, R. \& Bergsma, E. W. J. On the use of satellite-based digital elevation models to determine coastal topography. IEEE proceedings IGARSS, Jpn. (2019).

Dodet, G. et al. Wave runup over steep rocky cliffs. J. Geophys. Res. Ocean. 123(10), 7185-7205, (2018)

Dodet, G. et al., 2019. The contribution of wind generated waves to coastal sea level changes. Surv. Geophys.

Durand, M. et al. The surface water and ocean topography mission: Observing terrestrial surface water and oceanic submesoscale eddies. Proc. IEEE 98, 766-779, DOI: 10.1109/JPROC.2010.2043031 (2010).

Erkens, G., Bucx, T., Dam, R., de Lange, G. \& Lambert, J. Sinking coastal cities. Proc. IAHS 372, 189-198 (2015).

Hallegatte, S., Green, C., Nicholls, R. \& Corfee-Morlot, J. Future flood losses in major coastal cities. Nat. Clim. Chang. 3(9), 802-806 (2013).

Hauer, F. E. M. V. e. a., M.E. Sea-level rise and human migration. Nat Rev Earth Environ 1, 28-29 (2020).

Hinkel J, Lincke D, Vafeidis AT, Perrette M, Nicholls RJ, Tol RSJ, et al. Coastal flood damage and adaptation costs under 21st century sea-level rise. Proceedings of the National Academy of Sciences; 111: 3292-3297. https://doi.org/10.1073/pnas.1222469111 pmid:24596428, (2014)

IPCC report, 2018, Special Report on Global Warming of $1.5^{\circ} \mathrm{C}$ (SR15). http://www.ipcc.ch/report/sr15/, IPCC (2018).

Iribarren, C., Nogales, C. Protection des ports. XVIIth International Navigation Congress, Section II, Communication, 31-80, (1949)

Krien, Y., Dudon, B., Roger, J., Arnaud, G. \& Zahibo, N. Assessing storm surge hazard and impact of sea level rise in the lesser antilles case study of martinique. Nat. Hazards Earth Syst. Sci. 17, 1559-1571, (2017), DOI: 10.5194/nhess-17-15592017, 
Kulp, S. B., Strauss S.A. New elevation data triple estimates of global vulnerability to sea-level rise and coastal flooding. Nat Commun 10, 4844 (2019).

Lashley, C.H.; Bertin, X.; Roelvink, D.; Arnaud, G. Contribution of Infragravity Waves to Run-up and Overwash in the Pertuis Breton Embayment (France). J. Mar. Sci. Eng. (2019), 7, 205.

Latrubesse, E. M. et al. Damming the rivers of the amazon basin. Nature 546, 363-369 (2017).

Le Cozannet, G. L. et al. Quantifying uncertainties of sandy shoreline change projections as sea level rises. Sci. Reports 9(42)., (2019)

Le Traon PY, et al., (2019) From Observation to Information and Users: The Copernicus Marine Service Perspective. Front. Mar. Sci. 6:234. doi: 10.3389/fmars.2019.00234Luijendijk, A. et al. The state of the world's beaches. Sci. Reports 8, 6641 (2018).

McGranahan G, Balk D, Anderson B. The rising tide: assessing the risks of climate change and human settlements in low elevation coastal zones. Environment and Urbanization, (2007); 19: 17-37

Melet, A., Meyssignac, B., Almar, R. \& Le Cozannet, G. Under-estimated wave contribution to coastal sea-level rise. Nat. Clim. Chang. NCLIM-17091712 (2018).

Mentaschi, L., Vousdoukas, M., Pekel, J.-F., Voukouvalas, E. \& Feyen, L. Global long-term observations of coastal erosion and accretion. Sci. Reports 8, 12876 (2018).

Minderhoud, C. L. E. G. e. a., P.S.J. Mekong delta much lower than previously assumed in sea-level rise impact assessments. Nat Commun 10, 3847 (2019).

Moftakhari, H. R., Salvadori, G., AghaKouchak, A., Sanders, B. F. \& Matthew, R. A. Compound effects of sea level rise and fluvial flooding. Proc. Natl Acad. Sci. USA 114, 9785-9790 (2017).

Neumann, B., Vafeidis, A., Zimmermann, J. \& Nicholls, R. Future coastal population growth and exposure to sea-level rise and coastal flooding-a global assessment. PloS one 10, e0118571, DOI: doi:10.1371/journal.pone.0118571 (2015).

Nicholls, R. \& Cazenave, A. Sea-level rise and its impact on coastal zones. Science 328, 1517-1520 (2010).

Nicholls, R. et al. Coastal systems and low-lying areas: Climate change 2007: impacts, adaptation and vulnerability. In: Parry ML, Canziani OF, Palutikof JP, van der Linden PJ, Hanson CE (eds) Contribution working group II to fourth assessment report intergovernmental panel on climate change. Camb. Univ. Press. Cambridge, UK (2007).

Nicholls RJ, Hanson SE, Lowe JA, Warrick RA, Lu X, Long AJ. Sea-level scenarios for evaluating coastal impacts. Wiley Interdisciplinary Reviews: Climate Change, (2014); 5: 129-150.

Paprotny, D., Kreibich, H., Morales-Nápoles, O., Terefenko, P., Schröter, K. Estimating exposure of residential assets to natural hazards in Europe using open data. - Natural Hazards and Earth System Sciences (NHESS), 20, 1, 323-343., (2020)

Poate, T. G., McCall, R. T. \& Masselink, G. A new parameterisation for runup on gravel beaches. Coast. Eng. 117, 176-190 (2016). 
Non-peer reviewed EarthArXiv preprint

Prime, T., Brown, J. M. \& Platera, A. J. Flood inundation uncertainty: The case of a $0.5 \%$ annual probability flood event. Environ. Sci. Policy 59, 1-9 (2016).

Pujol, M.-I. et al., 2014: the new multi-mission altimeter data set reprocessed over 20 years. Ocean. Sci. 1067-1090 (2016).

Ranasinghe, R. On the need for a new generation of coastal change models for the $21^{\text {st }}$ century. Sci Rep 10, 2010 (2020). https://doi.org/10.1038/s41598-020-58376-x

Rueda, A. et al. A global classification of coastal flood hazard climates associated with large-scale oceanographic forcing. Sci. Reports 7, 5038 (2017).

Schwartz, M. Encyclopedia of Coastal Science, Springer, Dordrecht, (2003).

Scussolini, P. et al. Flopros: an evolving global database of flood protection standards. Nat. Hazards Earth Syst. Sci. 16, 10491061, DOI: 10.5194/nhess-16-1049-2016 (2016).

Serafin, K., Ruggiero, P. \& Stockdon, H. The relative contribution of waves, tides, and non-tidal residuals to extreme total water levels on us west coast sandy beaches. Geophys. Res. Lett. 44, 1839-1847 (2017).

Serafin, K. A., Ruggiero, P., Barnard, P. L. \& Stockdon, H. F. The influence of shelf bathymetry and beach topography on extreme total water levels: Linking large-scale changes of the wave climate to local coastal hazards. Coast. Eng. DOI: https://doi.org/10.1016/j.coastaleng.2019.03.012 (2019).Slangen et al., (2014)

Sterl, A. \& Caires, S. Climatology, variability and extrema of ocean waves: the web-based knmi/era-40 wave atlas. J. Climatol. 25, 963-977 (2005).

Stockdon, H. F., Holman, R. A., Howd, P. A. \& Sallenger Jr, A. H. Empirical parameterization of setup, swash, and runup. Coast. Eng. 53, 573-588 (2006).

Tadono, T. et al. Generation of the $30 \mathrm{~m}$-mesh global digital surface model by alos prism. Int. Arch. Photogramm. Remote. Sens. Spatial Inf. Sci. 157-162 (2016).

Tazkia A. R., Krien Y., Durand Fabien, Testut Laurent, Islam Akms, Papa Fabrice, Bertin X. Seasonal modulation of M2 tide in the Northern Bay of Bengal. Continental Shelf Research, 137, 154-162. ISSN 0278-4343, (2017)

Tebaldi, Strauss, Zervas. Modelling sea level rise impacts on storm surges along US coasts. Environmental Research Letters 7, 12 pp., (2012)

Vitousek, S. \& et al. Doubling of coastal fooding frequency within decades due to sea-level rise. Sci. Rep. 7 (2017).

Vousdoukas, M., Mentaschi, L., Voukouvalas, E. \& Feyen, L. Climatic and socioeconomic controls on coastal flooding impacts in europe. Nat. Clim. Chang. 8, 776-780 (2018).

Vousdoukas, M.I., Ranasinghe, R., Mentaschi, L. et al. Sandy coastlines under threat of erosion. Nat. Clim. Chang. 10, 260263 (2020). https://doi.org/10.1038/s41558-020-0697-0

Ward, P.J. et al,. Dependence between high sea-level and high river discharge increases flood hazard in global deltas and estuaries. Environ. Res. Lett. 13 084012, (2018)

Wessel, P. \& Smith, W. A global, self-consistent, hierarchical, high-resolution shoreline database. J. Geophys. Res. 101(B4), 8741-8743 (1996). 
412 Zhang, K. et al. Accuracy assessment of aster, srtm, alos, and tdx dems for hispaniola and implications for mapping 413 vulnerability to coastal flooding. Remote. Sens. Environ. 225, 290 - 306, DOI: https://doi.org/10.1016/j.rse.2019.02.028 414 (2019).

415

416 Acknowledgments

417 RR is supported by the AXA Research fund and the Deltares Strategic Research Programme 'Coastal and Offshore 418 Engineering' 
1

2 How waves are accelerating global coastal overtopping

3 Rafael Almar ${ }^{1,}{ }^{*}$, Harold Diaz ${ }^{1}$, Erwin W.J. Bergsma ${ }^{1}$, Roshanka Ranasinghe ${ }^{2,3,4}$, Angelique Melet $^{5}$,

4 Fabrice Papa ${ }^{1}$, Michalis Vousdoukas ${ }^{6}$, Panagiotis Athanasiou ${ }^{3,4}$, Olusegun Dada ${ }^{7}$, Luis Pedro

$5 \quad$ Almeida $^{8}$, and Elodie Kestenare ${ }^{1}$

6

7

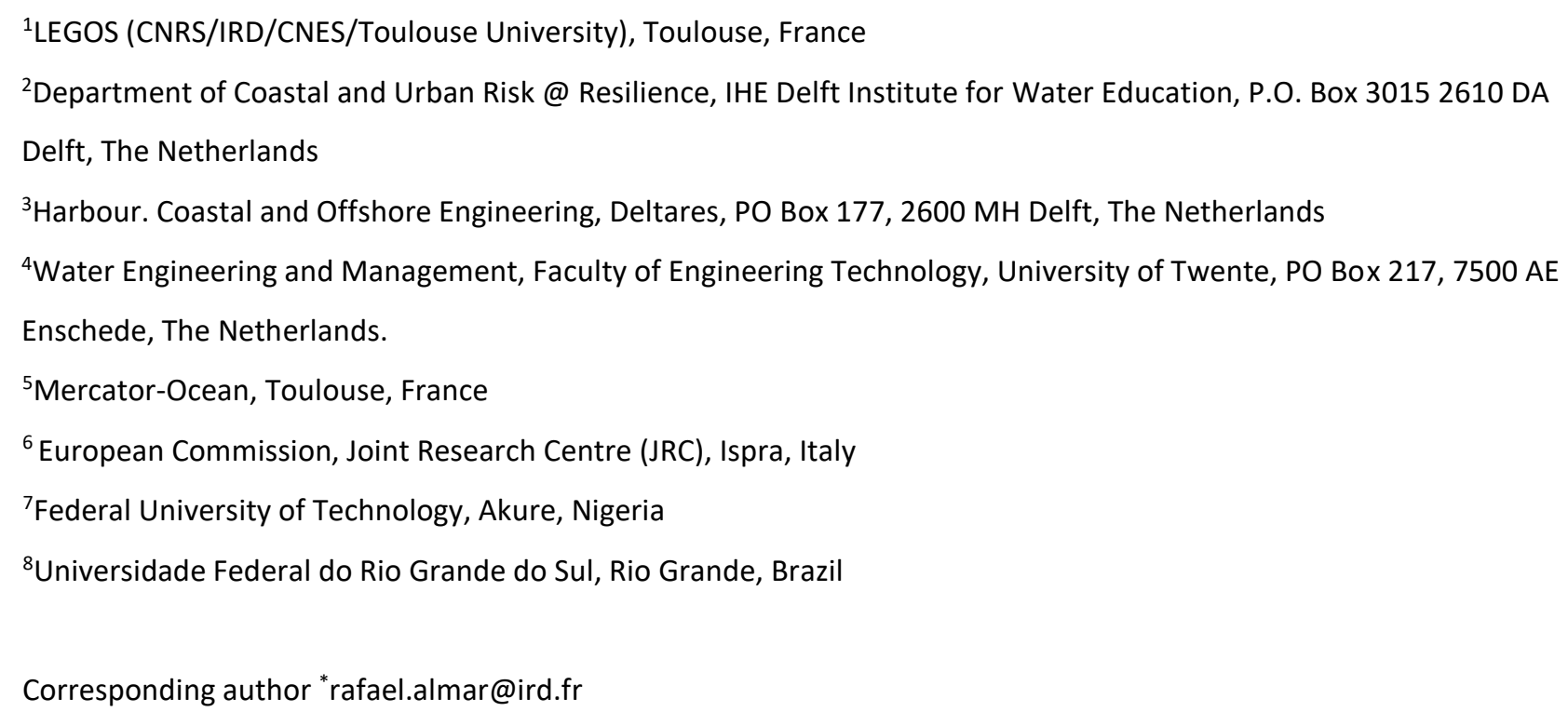




\section{S1. Separation of total water level at the coast trends}

Figure S1 illustrates the decomposition of components wave runup ( $R$ in Eq. 1), regional sea level (SLA in Eq. 1) and storm surge (DAC in Eq. 1, inverse barometer combined with high-frequency barotropic response of the ocean to atmospheric wind and pressure forcing) of sea level at the coast separately (we do not show astronomical tide but it was included in the computation). It is evidenced that the individual components have contrasting regional trend patterns and contributions to overtopping (Figure 3.a of the manuscript).

Figure S2 shows the 1993 -2015 trends computed from annual values in wave runup (R in Eq. 1), regional sea level (SLA in Eq. 1) and storm surge (DAC in Eq. 1) separately, and used to compute the trend in overtpping (Figure 3.b of the manuscript). As observed for the average values, the trends have contrasting regional trend patterns. In some areas (e.g. Caribbean, Bay of Bengal, Mekong delta) the contribution of all individual components add up to result in a higher overall trend of overtopping events, whereas in other areas (e.g. North Western Europe, southeastern coast of North America), some components cancel out the effect of others to result in small or negative trends in overtopping events.
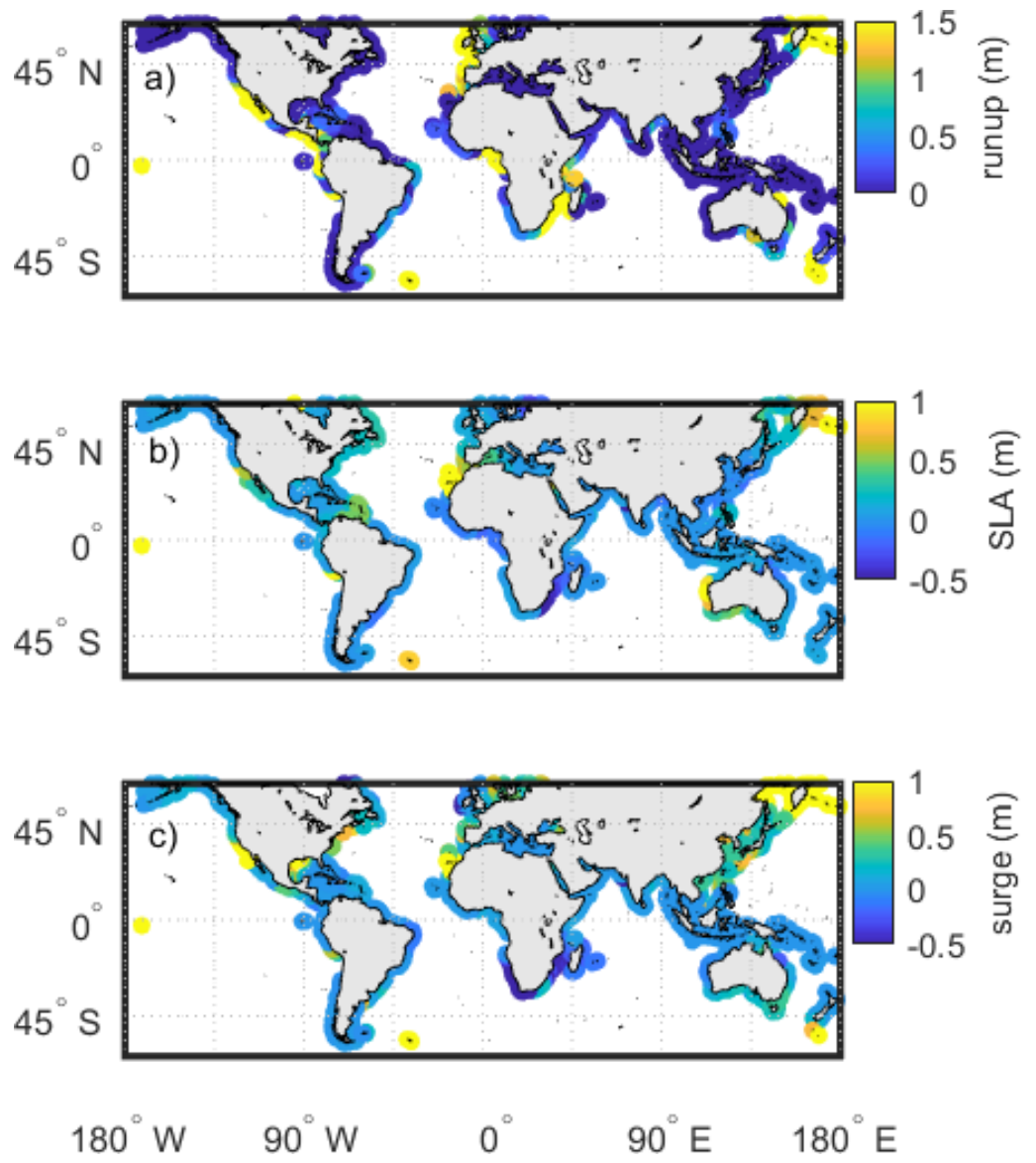

Figure S1. Contribution of a) wave runup (R), b) steric sea level (SLA) and c) storm surge (DAC) to the total overtopping (Figure 3.a). Values reflect each average components during the events. 

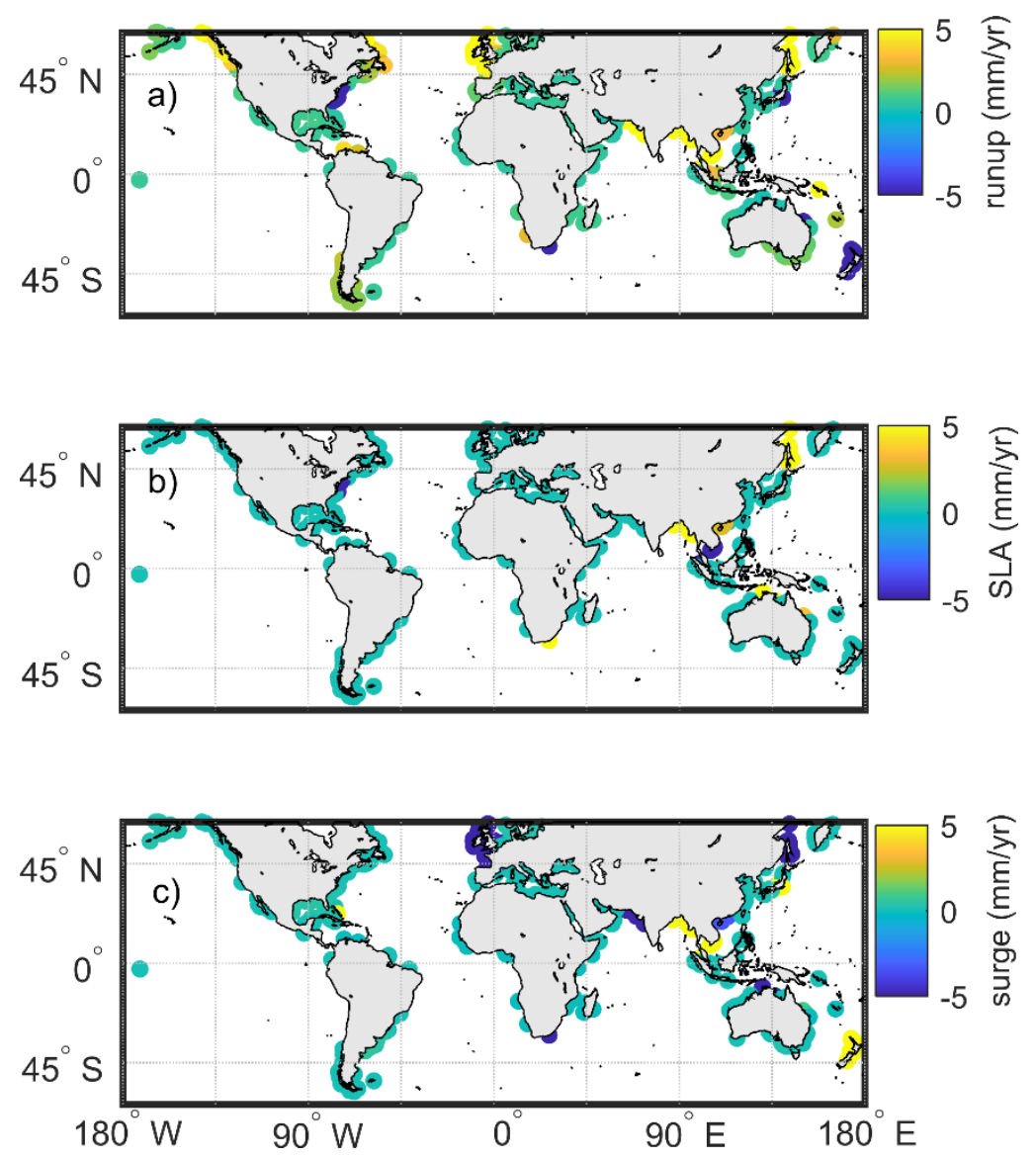

Figure S2. Contribution of a) wave runup (R), b) steric sea level (SLA) and c) storm surge (DAC) to the total overtopping trend

(Figure 3.b). These trends are computed from the annual values during the events.

\section{S2. Comparison of topography datasets}

The way in which the choice of the topography dataset may influence the overtopping results is investigated here. The capabilities of AW3D30 to derive coastal topography has been investigated in details in Diaz et al. (2019) at Capbreton, SW France and compared to other satellite-derived topography data sets. These results showed that AW3D30 has good skills to reproduce the topography of the upper beach (in the latter case), with an overall good estimate of absolute elevation. AW3D30 was found particularly capable of estimating coastal elevation such as for a dune. The drawbacks are the limitation in the intertidal area that is generally lacking from the dataset. Her the results obtained using AW3D30 were compared with different independent datasets, from the MERIT (SRTM) and GEBCO bathymetry dataset (Athanasiou et al., 2019). This latter dataset was used to obtain a second estimate, in addition to the AW3D30 one, of foreshore slopes that need to be used in wave runup formulae. To account for artificial coastal protection, the FLOod PROtection Standards FLOPROS (Scussolini et al., 2016) dataset was used to have a third estimate of coastal elevations and subsequent flooding (Vousdoukas et al., 2018). These three datasets were used randomly in the projections to reduce the dependence to a single one in our analyses.

The sensitivity of the overtopping projections to the topographic dataset used is investigated here. Figure $\mathbf{S} 2$ indicates that both FLOPROS and MERIT data bases generally provide lower estimates of maximum subaerial coastal elevation compared 
to AW3D-30, which would lead to more flooding when FLOPROS or MERIT is used in the computations (Figure S4). Figure S3 shows that nearshore slopes of GEBCO (slope computed between the depth of closure and the coastline) are milder when compared with the foreshore slopes of AW3D30 (average slope within the region determined by the shoreline and the distance given by the coast high), which would to less flooding when using the former. Interestingly, when MERIT and GEBCO are used for coastal elevation and slope respectively (for runup - see Figure S3), projected overtopping appears to be very close to those obtained when using AW3D30 (Figure S4).
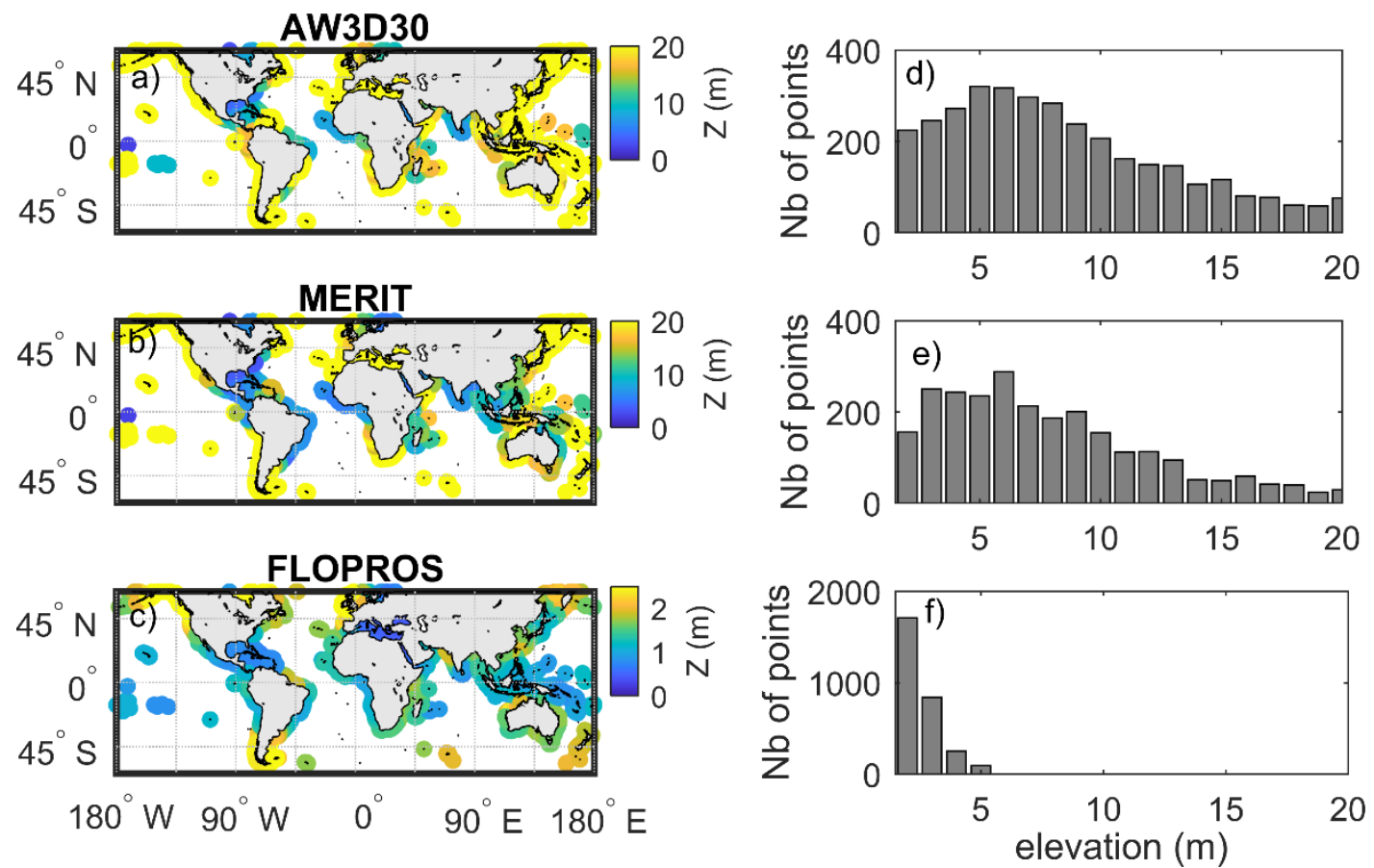

Figure S3. Global distribution of the maximum subaerial coastal elevation computed from 3 different datasets: AW3D30 (ALOS), MERIT (SRTM), and FLOPROS. Left hand subpanels show worldwide maps. Right hand column bar subpanels show the distributions. 

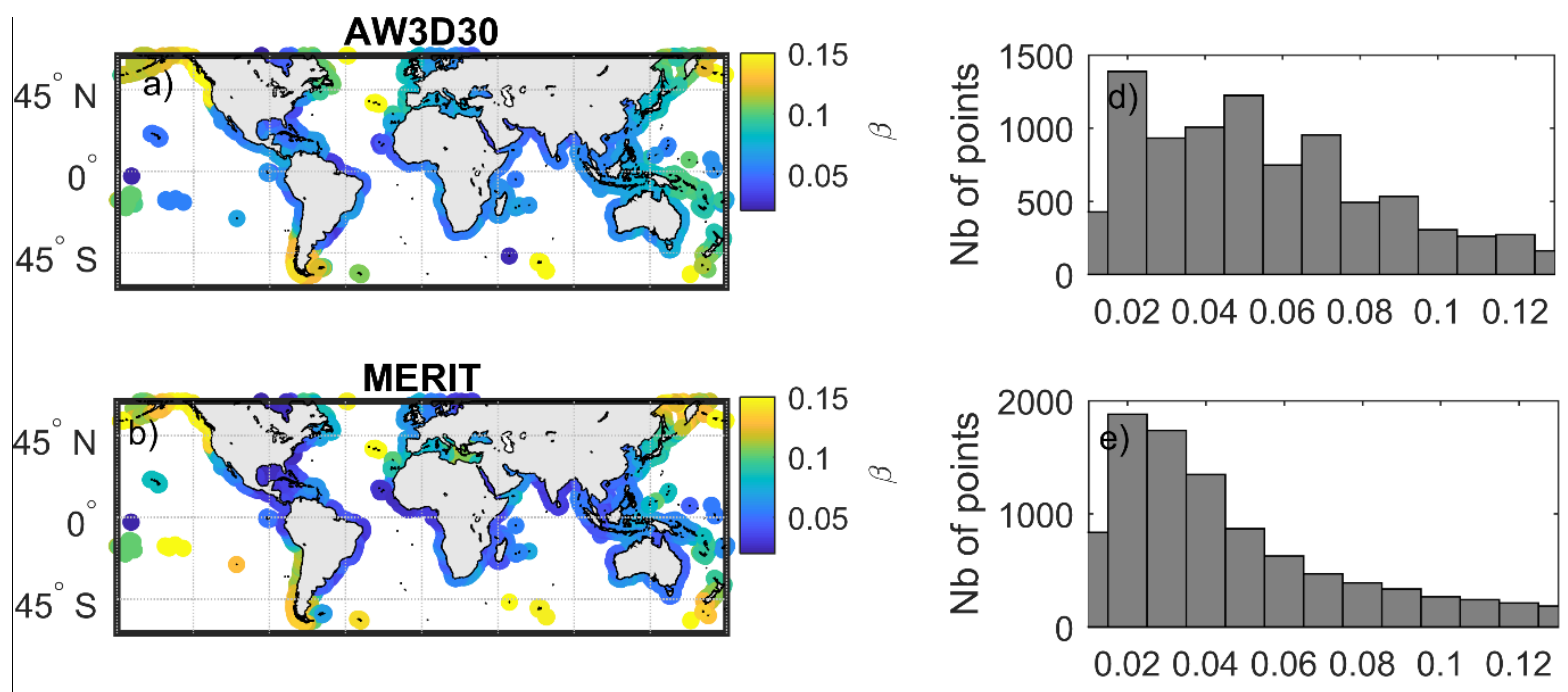

Figure S4. Global distribution of coastal slopes computed from 3 different datasets: AW3D30 (ALOS), MERIT (SRTM) and

GEBCO. Left panels show the spatial distribution with right panels showing the value distribution. Subaerial highs of AW3D30 and MERIT are computed ector is the maximum elevation found from the first local maxima, and slopes are calculated from the shoreline to the maximum elevation point. For GEBCO, the slope is the nearshore slope (from shoreline till depth of closure) as calculated in Athanassiou et al. (2019).
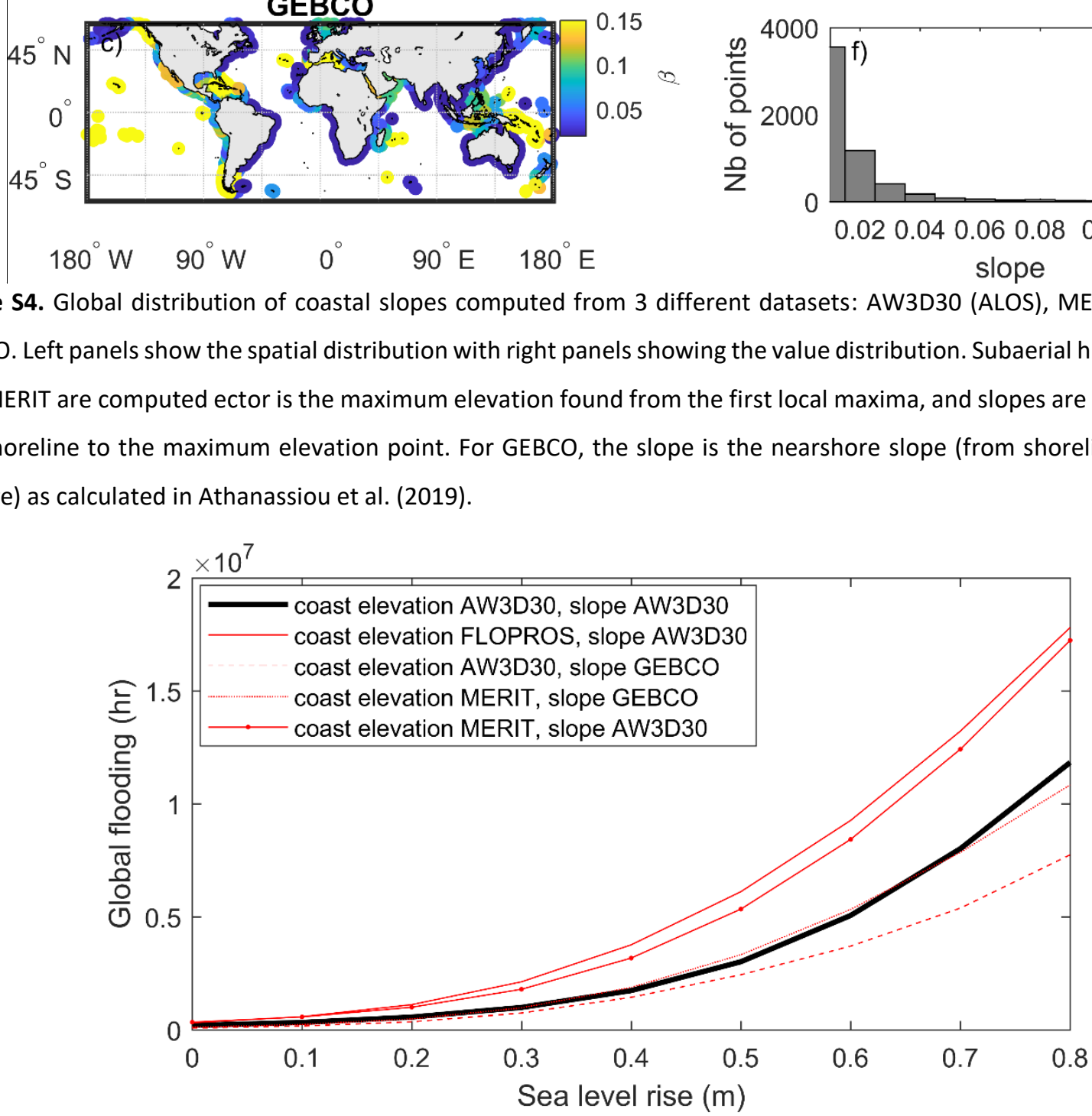

$180^{\circ} \mathrm{W} \quad 90^{\circ} \mathrm{W} \quad 0^{\circ} \quad 90^{\circ} \mathrm{E} \quad 180^{\circ} \mathrm{E}$
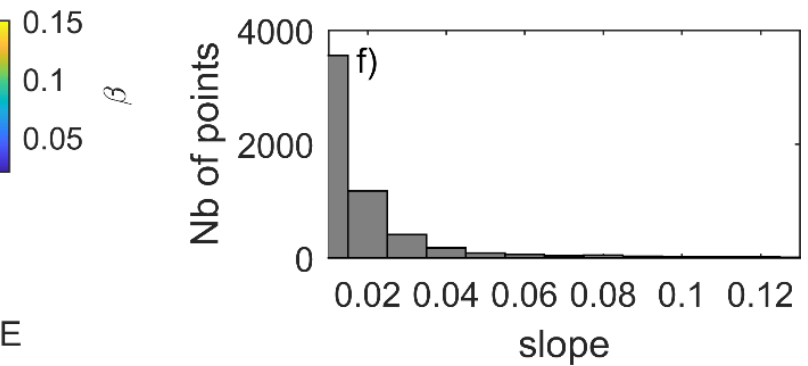

Figure S5. Sensitivity Globally integrated number of annual overtopping hours to the coastal topography datasets. The reference dataset used this study for the analyses is ALOS AW3D30 (coastal elevation and slope, thick black line). 


\section{S3. Validation of the overtopping computations for specific coastal flooding regional events} Here, the methodology adopted to compute overtopping is tested for fourdocumented major events (Figure S6) along the West Europe Atlantic coast (Figure S6.a, Xynthia storm in France, Bertin et al., 2012), Gulf of Mexico (Figure S6.b, Katrina hurricane in USA, Fritz et al., 2007), Mediterranean South-East coast (Figure S6.c, Nile delta in Egypt; Frihy et al., 2010; Refaat and Eldeberk, 2016; Ismail, et al., 2012), Gulf of Guinea, West Africa (Figure S6.d, Lagos in Nigeria; Nwilo et al., 1997; Olaniyan and Afiesimama, 2003) and Majuro in Marshall Pacific Islands (Figure S6.e, Hoeke et al., 2013). The goal is to assess whether our method is able to reproduce the regional sea level at the coast by comparing our calculations with sea level tide-gauge timeseries from the Global Extreme Sea Level Analysis (GESLA) dataset (Woodworth et al., 2017). Finally, the potential of overtopping is investigated by comparing the total sea level at the coast including wave runup. Regional AW3D30 coastal elevations compare well with levels reported in the literature (South West France in Diaz et al. (2019) and around the Iberian Peninsula in Zhang et al., 2018). Our Regional sea levels (TWL minus wave runup) estimate (dashed black) also show a good agreement when compared with GESLA tidal gauges (thin black). It is interesting to observe that regional sea level alone cannot be responsible for overtopping and flooding in these study cases. It is only when wave runup is added that the water level overpasses the coastal elevation maxima for these 4 events. This is evident for the Gulf of Guinea case (Figure S6.d) where large tidal (spring) amplitude cannot induce overtopping alone which actually happen with large waves when tide amplitude already reduced. This is particularly the case for Lagos and Pacific Islands events where the flooding is due to distant swell (Hoeke et al., 2013; Ford et al., 2018) by contrast with local storms associated with strong winds and surge (i.e. Xynthia and Katrina). 

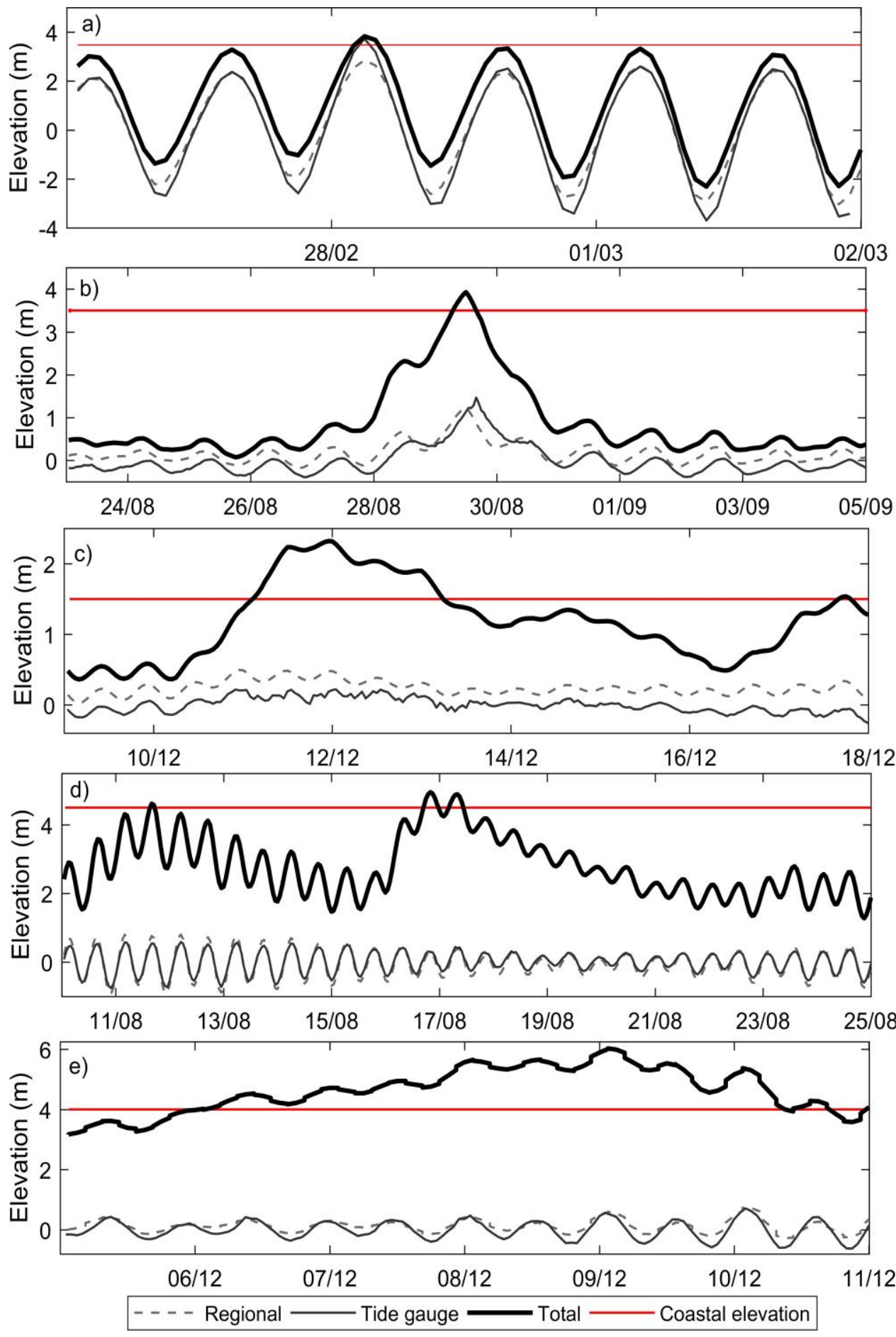

Figure S6. Validation of event detection with reported flooding through overtopping: a) along the West Europe Atlantic coast (Xynthia storm in France, Bertin et al., 2012), b) Gulf of Mexico (Katrina hurricane in USA, Fritz et al., 2007), c) Mediterranean South-East coast (Nile delta in Egypt; Frihy et al., 2010; Refaat and Eldeberk, 2016; Ismail, et al., 2012), d) Gulf of Guinea, West Africa (Lagos in Nigeria; Nwilo et al., 1997; Olaniyan and Afiesimama, 2003) and e) Majuro in Marshall Pacific Islands (Hoeke et al., 2013). Our TWL minus wave runup estimate (dashed black) is compared with GESLA tidal gauges (thin black). 
Total sea level at the coast, including wave runup (thick black) is compared to coastal elevation reported in the literature. Overtopping/flooding happen if total sea level is larger than maximum coastal elevation considered for overtopping.

\section{REFERENCES}

Athanasiou, P., van Dongeren, A., Giardino, A., Vousdoukas, M., Gaytan-Aguilar, S., and Ranasinghe, R.: Global distribution of nearshore slopes with implications for coastal retreat, Earth Syst. Sci. Data, 11, 1515-1529, https://doi.org/10.5194/essd-11-1515-2019, (2019).

Bertin, X., Bruneau, N., Breilh, J.-F., Fortunato, A. B. \& Karpytchev, M. Importance of wave age and resonance in storm surges: The case xynthia, bay of biscay. Ocean. Model. 42, 16 - 30 (2012).

Diaz, H., Almar, R. \& Bergsma, E. W. J. On the use of satellite-based digital elevation models to determine coastal topography. IEEE proceedings IGARSS, Jpn. (2019).

Ford, M., Merrifield, M. \& Becker, J. Inundation of a low-lying urban atoll island: Majuro, marshall islands. Nat. Hazards 91(3), 1273-1297 (2018).

Frihy, O., Deabes, E. \& El Gindy, A. Wave climate and nearshore processes on the mediterranean. J. Coast. Res. 26(1), 103112 (2010).

Fritz, H. M. et al. Hurricane katrina storm surge distribution and field observations on the mississippi barrier islands. Estuarine, Coast. Shelf Sci. 74, 12 - 20 (2007).

Hoeke, R. et al. Widespread inundation of pacific islands triggered by distant-source wind-waves. Glob. Planet. Chang. 108, 128-138 (2013).

Ismail, N., Iskander, M. \& El-Sayed, W. Assessment of coastal flooding at southern mediterranean with global outlook for lowland coastal zones. Coast. Eng. Proc. 33(83), 1-13 (2012).

Nwilo, P. C. Managing the impacts of storm surges on victoria island, lagos, nigeria. Destr. Water: Water-Caused Nat. Disasters, their Abat. Control. IAHS Conf. held at Anaheim, California, June 1996 239, 325-330 (1997).

Olaniyan, E. \& Afiesimama, E. Understanding ocean surges and possible signals over the nigerian coast: a case study of the

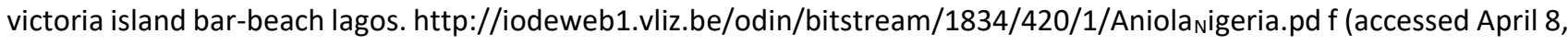
2019) (2003).

Refaat, M. \& Eldeberky, Y. Assessment of coastal inundation due to sea-level rise along the mediterranean coast of egypt. Mar. Geod. 39:3-4, 290-304 (2016).

Scussolini, P. et al. Flopros: an evolving global database of flood protection standards. Nat. Hazards Earth Syst. Sci. 16, 10491061, DOI: 10.5194/nhess-16-1049-2016 (2016).

Vousdoukas, M. L. V. E. V. M. J. S. J. L. F. L., M.I. Global probabilistic projections of extreme sea levels show intensification of coastal flood hazard. Nat. Commun. 9, 2360 (2018). 
Non-peer reviewed EarthArXiv preprint

142 Woodworth, P.L., Hunter, J.R. Marcos, M., Caldwell, P., Menendez, M. and Haigh, I. 2017. Towards a global higher-frequency 143 sea level data set. Geoscience Data Journal, 3, 50-59, doi:10.1002/gdj3.42. 